\title{
Las TIC en la intersección áulica: desafíos y tensiones de la alfabetización digital en la escuela media
}

\section{ICT in the Classroom Intersection: Challenges and Tensions in Digital Literacy in High Schools}

\author{
Joaquín Linne (*) https://orcid.org/0000-0002-4297-3914 \\ (*) Consejo Nacional de Investigaciones Científicas y Técnicas \\ (Recibido: 30 de mayo de 2019; Aceptado para su publicación: 3 de diciembre de 2019)
}

Cómo citar: Linne, J. (2020). Las tıc en la intersección áulica: desafíos y tensiones de la alfabetización digital en la escuela media. Revista Electrónica de Investigación Educativa, 22, e24, 1-13. https://doi.ora/10.24320/redie.2020.22.e24.3072

\section{Resumen}

Este artículo indaga tensiones en torno a la alfabetización digital en la escuela media en Argentina. A nivel metodológico, se realizaron 20 entrevistas en profundidad: 15 a docentes y 5 a directivos que trabajan en escuelas del país, mayormente del Área Metropolitana de Buenos Aires. También se llevaron a cabo observaciones presenciales en 6 escuelas y observaciones virtuales en foros en los que se discuten estas problemáticas. En los resultados se evidencia que las netbooks entregadas por el Estado entre 2010 y 2015 contribuyeron a la alfabetización digital de millones de estudiantes, en particular en sectores populares. Asimismo, se vislumbra que el proyecto del "aula digital móvil" (iniciado en 2015) tiene aceptación por parte de la mayoría de directivos y docentes, aunque adviertan sobre la escasez de conectividad, presupuesto y capacitación. Por último, se observa que el teléfono móvil, principal dispositivo utilizado, se presenta de manera ambivalente respecto a su potencial áulico.

Palabras clave: TIC, alfabetización digital, escuela media, teléfono móvil, computadora portátil.

\section{Abstract}

This article explores the tensions surrounding digital literacy in high schools in Argentina. The methodology employed consisted in 20 in-depth interviews: 15 with teachers and 5 with members of administrative staff in schools across the country, mostly in the Buenos Aires Metropolitan Area. In addition, in-person observation was conducted in 6 schools, together with virtual observation in discussion forums dealing with these issues. The results show that the netbooks provided by the state between 2010 and 2015 have helped boost the digital literacy skills of millions of students, particularly in less affluent sectors. Furthermore, the study suggests that the "mobile digital classroom" project (launched in 2015) has been largely welcomed by teaching and administrative staff, although they warn of a lack of connectivity, funding and training. Lastly, it was found that cellular phones - the main device used - evoked mixed feelings with regard to their potential in the classroom.

Keywords: ICT, digital literacy, middle school, cellphone, laptop computers. 


\section{Introducción}

Ante el creciente interés social y juvenil por utilizar las TIC, la comunidad educativa tiene posiciones ambivalentes respecto a su uso en el aula. ¿Constriñen la reflexión, el cálculo lógico-matemático y la lectoescritura, o contribuyen a adquirir y transmitir conocimientos, a la vez que estimulan la inteligencia y las capacidades para resolver problemas velozmente? En todo caso, se debate cómo reorganizar sus actividades incorporando estas tecnologías. En este contexto, la pregunta que todos parecen querer hacerle a Internet es "cómo repensar y modificar las prácticas áulicas".

Dentro de los diversos estudios que señalan las virtudes de las TIC para la educación, Huertas y Pantoja (2016) advierten que las generaciones jóvenes se encuentran poco motivadas por el paradigma educativo tradicional. Esta situación requiere que la comunidad educativa desarrolle estrategias que atraigan y comprometan al estudiantado, en gran medida relacionadas con las TIC. No obstante, si bien éstas proveen recursos motivadores e innovadores, no aseguran aprendizajes comprensivos, creativos y críticos. Ante esto, es clave la figura del docente, quien debe utilizarlas como medio para facilitar el aprendizaje, interviniendo en distintas instancias para aclarar el contenido y ser lo más claros posibles respecto a la utilidad de lo que se está aprendiendo y sobre cómo evaluar. Arancibia y Bustamante (2019) coinciden con Huertas y Pantoja (2016) y, además, evidencian que el uso de la pizarra digital interactiva eleva la motivación del alumnado y potencia el aprendizaje.

Con una mirada ambivalente, Noshahr et al. (2014) plantean que no existe relación entre el rendimiento académico y el uso educativo de las TIC, al no hallarse una correlación significativa entre notas académicas y tiempo dedicado al uso de tecnologías. Por su parte, García-Martín y Cantón-Mayo (2019) advierten que las TIC pueden tener un impacto positivo en algunas áreas y negativo en otras.

Desde un enfoque crítico, Linne (2018) señala la tendencia a obtener mejores resultados académicos en quienes apagan la computadora durante un tiempo, lo que sugiere que las TIC no siempre potencian un multitasking "productivo". Sola et al. (2019) y Díaz-Vicario et al. (2019) advierten sobre la tendencia al uso constante de redes sociales junto con un escaso control parental, lo que deviene en falta de autocontrol y usos nocivos de las TIC en algunos jóvenes, quienes no se reconocen vulnerables, pero sí visibilizan usos problemáticos en sus pares.

En este contexto, Park (2017) señala que a mayor capital cultural tiende a aumentar el uso académico de las TIC. No obstante, propone reemplazar el concepto de capital cultural por el de capital digital para distinguir las competencias tecnológicas estudiantiles, dado que nadie nace con la habilidad para utilizar tecnologías, sino que debe aprenderlas.

Respecto al paradigma educativo tradicional, en el que el saber docente no solía cuestionarse, Armella (2016), De la Iglesia (2019), Kozak (2016) y Urresti (2015) coinciden en que las TIC resultan un desafío porque implican la progresiva redefinición de lo que se asocia a conocimiento, resignifican las concepciones de los sujetos y las fuentes válidas como citas de autoridad. A su vez, destacan que la masificación acelerada de estas tecnologías promueve culturas participativas, interacción entre pares y creación compartida de contenidos, lo que también genera tensiones en el sistema educativo.

Almirón (2015), Blanco et al. (2018) y Beltrán-Sánchez et al. (2019) sostienen que la mayoría de los docentes se manifiesta a favor de las TIC, ya que motivan al alumnado. No obstante, las utilizan ocasionalmente en el aula debido a tres razones: falta de tiempo, infraestructura y capacitación. Asimismo, indican que numerosos docentes creen que Internet dispersa a los estudiantes, ante lo que temen perder el control de la clase. De esta manera, como señala Matamala (2018), las tecnologías tienden a ser herramientas ornamentales más que decisivas en el proceso educativo áulico.

En un informe sobre el uso de las TIC en Argentina, Gruschetsky y Serra (2001) señalan que para el cambio de milenio sólo la mitad de las escuelas poseía al menos una computadora. De éstas, menos de la mitad contaba con Internet. Asimismo, revelan que existía una computadora por cada 90 estudiantes, con 140 estudiantes por computadora en el caso estatal y 40 en el sector privado. Si bien estos datos fueron 
mejorando lentamente a lo largo de la década, sólo a partir de 2010 se desplegó un decidido programa a nivel nacional para incrementar la tecnología en escuelas públicas. Desde ese año, el Programa Conectar Igualdad (PCI) repartió alrededor de cinco millones de netbooks a estudiantes y docentes de escuelas públicas, contribuyendo a la alfabetización tecnológica de millones (Benítez, 2018; Lemus, 2017; Welschinger, 2016; Zukerfeld, 2018).

Con una mirada más crítica, Cabello (2017) advierte que las políticas públicas suelen contribuir a la apropiación de tecnologías en relativo desuso dentro de la cultura digital juvenil. En el caso de las netbooks, representaron avances parciales en cuanto a la inclusión tecnológica en las aulas debido, principalmente, a los problemas de conectividad en las escuelas, a la limitada inversión estatal en formación docente y a que el principal dispositivo utilizado por la gran mayoría son los teléfonos. Limitaciones similares indican de Lima y Moreira (2019) respecto a las políticas públicas de inclusión tecnológica en Brasil.

Diversas investigaciones (García-Martín y Cantón-Mayo, 2019; Linne, 2018) coinciden en que las herramientas más utilizadas para estudiar son el paquete Office (o similares programas en versión gratuita), motores de búsqueda, wikis, blogs, páginas web, redes sociales y mensajería instantánea. No obstante, Ortiz-Colón et al. (2018) y Martín (2018) advierten que el principal uso de las TIC por parte de los jóvenes es para jugar. En este sentido, aconsejan introducir la gamificación en el aula, a la que definen como plantear un proceso o consigna como juego. Estos autores coinciden con Qian y Clark (2016) y López (2016) en que los "juegos serios" y la gamificación en las aulas elevan la motivación estudiantil, la creatividad y la implicación del estudiantado con las tareas, potencia el trabajo en equipo y estimula el desarrollo de habilidades tecnológicas.

En la revisión de los antecedentes se distinguen tres posiciones: una ambivalente respecto al uso áulico de estas tecnologías; una crítica ante cierta fascinación ingenua y fetiche con los dispositivos, y la última, a favor de integrar las TIC a las aulas a partir del juego. En todo caso, estas tecnologías llegaron para quedarse y es necesario abrir el debate a la comunidad educativa. Es evidente que Internet no puede responder por nosotros.

\section{Método}

Se realizó un trabajo de campo cualitativo durante la segunda mitad de 2018 y el primer cuatrimestre de 2019. Dado que la mayoría de los estudios se centran en la mirada estudiantil, en esta ocasión buscar el enfoque desde la perspectiva de otros actores de la comunidad educativa: docentes y directivos. En todos los casos, para resguardar su anonimato, sólo se menciona el rol, provincia o localidad, y edad del participante.

El diseño metodológico fue cualitativo y exploratorio-descriptivo. Se basó en una muestra intencional y combinó dos herramientas: observaciones y entrevistas. En primer lugar, se hicieron observaciones presenciales en seis escuelas del Área Metropolitana de Buenos Aires (AMBA), tanto de instituciones ubicadas en la Provincia de Buenos Aires como en la ciudad. También se efectuaron observaciones virtuales participantes en foros en los que docentes o directivos discuten estas problemáticas. A estos foros se accedió a través de la red social Facebook y del campus virtual de la Universidad Nacional de Lanús.

Respecto a la segunda herramienta, se hicieron 20 entrevistas en profundidad: 5 a directivos de escuelas del AMBA y 15 a docentes de distintas provincias de Argentina (Buenos Aires -Provincia y Ciudad-, Chubut, Río Negro, Salta, Catamarca y Jujuy). En ambos casos se trató de una muestra no probabilística e intencional a la que se le aplicó un cuestionario con preguntas abiertas de creación propia. Los directivos poseen entre 55 y 70 años; 3 son mujeres y 2 varones. Los docentes tienen entre 30 y 60 años; 8 son mujeres y 7 varones. De la muestra intencional de 5 directivos, 2 directivos poseen posgrado (un doctorado y una maestría), 2 licenciaturas y uno estudios terciarios (profesorado). De la muestra de 15 docentes, 2 poseen estudios de posgrado, 5 realizaron estudios de grado y 8 terciarios (6 profesorados y 2 tecnicaturas). 
Se utilizó el método de bola de nieve para construir la muestra de docentes. Fueron contactados vía conocidos en común, a través de contactos institucionales generados en trabajos de campo de investigaciones previas y por medio de plataformas digitales. En las entrevistas en profundidad, así como en los foros virtuales, directivos y docentes fueron consultados acerca de sus experiencias cotidianas con estas tecnologías, sus percepciones en torno a los usos estudiantiles, sus imaginarios tecnológicos, qué critican y qué valoran del uso de las TIC en las escuelas y qué recomiendan en torno a su integración áulica.

Posterior al trabajo de campo se procedió al análisis de los datos, tanto de las notas tomadas durante las observaciones como de las grabaciones de las entrevistas. El análisis de datos se enriqueció con elementos procedentes de nuestra experiencia como docentes, tanto en ámbitos presenciales como virtuales. Asimismo, el análisis se nutrió de la revisión constante del estado del arte y de las discusiones en los grupos de investigación de pertenencia, tanto en el Instituto Gino Germani de la UBA como en fLACSO Argentina.

\section{Resultados}

\subsection{La sala de informática: aislada y con límites claros}

La sala de informática es el modo más tradicional de incluir las TIC en las instituciones de educación formal. Como señalan Gruschetsky y Serra (2001), para el 2001 menos del 10\% de las escuelas argentinas contaba con altos recursos tecnológicos, entendidos como una sala de informática, un profesor de computación y acceso a Internet.

En esta sala cada estudiante cuenta con una computadora de escritorio y las actividades son coordinadas por un docente específico o facilitador tecnológico, quien enseña a utilizar programas. Algunos docentes señalan que aquí la integración tecnológica suele funcionar de modo menos problemático que en el modelo 1 a 1 de netbooks en comodato, donde el mantenimiento y cuidado del aparato quedó a cargo del estudiante.

El uso de la sala de informática es constante. En nuestra escuela usamos la sala y además tenemos notebooks para trabajar en biblioteca o en las aulas. Suele haber algunos problemas con los programas que son muy específicos, como los de diseño gráfico o música. El uso de la sala es muy enriquecedor, sobre todo si contás con el apoyo de un docente del área que a su vez pueda sumar contenidos específicos de su materia. De todos modos, en mi caso particular, que doy Lengua, no hay nada que le pida a mis alumnos que no se pueda resolver con un celular. (Entrevista, docente, 33, AMBA)

Por lo general, se aprenden funciones de los programas principales del paquete Office o en versiones gratuitas similares, para escribir textos, editar imágenes o videos, armar cuadros y hojas de cálculo. En efecto, en la mayoría de las salas de informática se enseña sobre los programas más populares de Windows: Word, Excel y Power Point. En escuelas técnicas también suelen enseñarse programas como Photoshop y Autocad. Más allá de las limitaciones de concurrir a la sala de informática una o dos veces por semana, este modelo conlleva otras limitaciones.

Pedir la sala de computación es casi una misión imposible. Hay que rastrear al de informática, ver si tiene un lugarcito para vos, rogar que no te eche la culpa de que una compu no anda después. (Entrevista, docente, 36 años, AMBA)

En consonancia con Kozak (2016), concurrir sólo una vez por semana a la sala de computación resulta escaso para desplegar competencias digitales útiles para el mercado académico y laboral. Reducir las actividades a programas de Windows no involucra procesos de alfabetización digital de mayor complejidad, como aprender sobre cuestiones vinculadas a programación, robótica, estadística, diseño y, en particular, búsqueda y selección de materiales y recursos alrededor de la web y de las distintas aplicaciones y programas disponibles. 
A diferencia de la emergente "aula digital móvil" (ADM), la tradicional sala de informática sigue brindando límites claros y un docente especializado en la materia. Sin embargo, se mantiene "quieta" y, en ocasiones, no se renueva. Su transformación a lo largo de la última década se encuentra relacionada con la masificación de los planes 1 a 1 y las tecnologías móviles.

\subsection{Las netbooks. inclusión digital con dificultades de aplicación}

La mayoría de docentes y directivos tiene una visión ambivalente del PCI. Por un lado, reconocen que la falta de recursos en torno a la capacitación, la conectividad y la asistencia técnica impidieron en muchas escuelas un funcionamiento armónico de los dispositivos. Por otro lado, valoran que las netbooks sirvieron para democratizar el uso de las TIC.

Рara una significativa parte de estudiantes de sectores populares (y de sus familiares), las netbooks representaron sus primeras computadoras.

Las netbooks del Conectar le vinieron bien a los que no tenían computadora. Pero en muchos casos las usaban principalmente para jugar en red. O se les rompían o bloqueaban, y el service en general tardaba tantos meses que los pibes se cansaban de esperar. (Entrevista, directivo, 55, AMBA).

El plan tenía el concepto de inclusión digital socioeducativa. No sólo educativa justamente porque los equipos llegaban donde de otra manera no hubieran llegado. Si bien faltaba conectividad en más de la mitad de las escuelas, no era imprescindible, menos hace 8 años cuando empezó. (Entrevista, docente y directiva, 49 años, Río Negro).

Para millones de estudiantes de bajos recursos socioeconómicos las netbooks, del PCI significaron alfabetización tecnológica e inclusión ciudadana. No obstante, en la mayoría de las aulas presentaron inconvenientes.

Nunca pudimos hacer un uso útil de las netbooks, tardaban mucho en encender y apagarse, alguna se tildaba o se había roto, o se la olvidaban, o no la tenían o no les funcionaba por alguna razón. O las tenían pero las usaban para jueguitos y no para el tema de la clase. (Entrevista, docente, 52, AMBA).

Entre que todos tengan listos las netbooks y los programas y logren concentrarse, se iba buena parte de la clase, lo que dificultaba implementar el uso de tecnologías en el aula efectivamente. (Entrevista, docente, 43 años, Salta).

Debería haber sido una política asistencial, y en gran parte lo fue. Pero no una política educativa. En un momento sirvió pero faltó preparación de los docentes, conectividad, y un sistema más veloz de reparación de los dispositivos. (Entrevista, docente, 44, Río Negro).

Si bien los y las estudiantes suelen estar a favor de utilizar las TIC en las aulas, los docentes tienen más reparos.

\subsection{El "aula digital móvil": moderado acierto con baja inversión}

A diferencia del PCl, desfinanciado y discontinuado por el gobierno actual, el proyecto ADM consiste en la dotación de una o dos de estas "aulas" a cientos de escuelas de nivel inicial y medio de gestión estatal del país. Esta acción se enmarca dentro del plan de educación digital nacional. De manera similar al PCl, la iniciativa promueve la incorporación pedagógica de las TIC para facilitar la alfabetización digital. El carro de las ADM, que cumple las funciones de carga, guarda y transporte, suele contener los siguientes implementos: 
- 30 netbooks (una para el docente, con contenido específico)

- Servidor pedagógico

- UPS (unidad de alimentación ininterrumpida)

- Router inalámbrico para trabajar en red

- Pizarra digital

- Proyector

- Cámara de fotos

- Impresora multifunción

- Tres pendrives

El ADM puede tener 30 netbooks o menos, cuando la matrícula de la escuela es menor. El carro es llevado a un aula a pedido del docente encargado de esa clase, quien debe reservarlo con tiempo. Una de sus principales ventajas es que no requiere piso tecnológico ni condiciones mínimas de infraestructura de la red escolar para funcionar. Todo lo que necesita se incluye en el "carrito" de guardado. A diferencia del $\mathrm{PCl}$, aquí el universo de interacción se propone más regulado, ya que al contar con un servidor por aula cada docente monitorea los sitios con los que sus estudiantes interactúan.

Pese a la escasez de presupuesto para la educación pública que este gobierno exacerbó, el "carrito tecnológico" es valorado por numerosos docentes y directivos. En efecto, distintos testimonios aseguran que el uso más acotado, en relación con el de las netbooks anteriores, se presenta como menos problemático y más productivo.

La mayoría de estudiantes a los que se les entregó computadoras del Conectar u otro plan, al poco tiempo ya no les andaban, se rompían, se bloqueaban y quedaban en la casa y no las traían al colegio a desbloquear. Otros le metieron mano, las desbloquearon y las rompieron. El plan hubiera sido bueno si las compus quedaban en la escuela y, como hacen ahora con los carros, los estudiantes sólo puedan usarlas allí. (Entrevista, docente, 46 años, AMBA)

Muchos docentes valoran del "carrito tecnológico" que los estudiantes tengan sus dispositivos cuando necesitan utilizarlos. Docentes y estudiantes valoran el resto de los dispositivos del ADM, como la pizarra digital, el proyector, la UPS, el router y el servidor. A su vez, los Facilitadores de Educación Digital también son valorados por la comunidad educativa. Estos tienen un plan de visitas periódico a las escuelas para verificar el estado del ADM, brindar asistencia técnica y extender certificados para evitar bloqueos de las netbooks. Preguntamos a directivos y docentes qué opinan de las ADM y qué harían si fuesen responsables de incluir las TIC en aulas de nivel medio y contasen con presupuesto.

Los carritos tecnológicos son muy completos. Aseguraría la capacitación de los docentes por etapas, inicialmente les daría un portafolio de actividades que podrían desarrollar a modo de sostén hasta que tomen confianza con la incorporación de las TIC mientras se capacitan. Compartiría las producciones, para que puedan ser copiadas, reproducidas y mejoradas o simplemente transformadas. Y como todo proceso sin retribución económica, es difícil sustentar procesos de mejora de calidad; sé que puede sonar mal, pero es la realidad de las empresas con procesos exitosos: el incentivo. La performance más fácil de aplicar es el trabajo por proyectos multidisciplinar; esto traería la ventaja de tener al profesor de TIC incluido en procesos transversales, e incluir la competencia y el juego. Esto entusiasma, fija objetivos y anima a trabajar grupalmente. (Entrevista, directiva, 55 años, AMBA).

Respecto al carrito tecnológico, primero me informaría del proyecto educativo de la institución, luego ver el nivel de manejo o el conocimiento y la predisposición del grupo de docentes. Es importante el espacio físico y las horas destinadas. Si no hay quien esté con los chicos en el aula, la docente no puede hacer la capacitación, y a contraturno, sin remuneración, es difícil. Comenzaría por reconocer el dispositivo, lo que tiene cargado, qué necesita conexión, cómo hacer una carpeta, guardar, almacenar, descargar videos, imágenes, etc. Luego solicitaría que traigan la planificación y piensen qué tema les gustaría trabajar con la compu. Y pensar un 
pequeño proyecto, que trabajarían primero la docente con el facilitador y, una vez definido, lo extenderíamos a los alumnos. (Entrevista, docente, 53 años, Río Negro).

Es importante generar confianza y acompañamiento. Una buena idea son los proyectos interdisciplinares para trabajar con el profe de TIC, aunque a veces delegan todo el trabajo a este último. Cuando llegaban los facilitadores tecnológicos, muchos docentes se iban porque eran los de "informática". También desde Dirección y desde el proyecto de la escuela debe plantearse como una meta el uso de las TIC. El carrito es una buena idea. Pero llenar la escuela de dispositivos no garantiza por sí solo un avance en el uso de las TIC. (Entrevista, docente, 58 años, AMBA).

Los docentes reclaman proyectos interdisciplinares en conjunto entre docentes de distintas materias y facilitadores tecnológicos, y que los directivos impulsen el uso de las TIC. A su vez, solicitan mayor libertad y recursos para utilizar las tecnologías, lo que implica que las capacitaciones sean pagadas si representan horas extra, o que alguien quede a cargo del aula si son en horas de clase.

La escuela contaba con dos carros de 30 netbooks cada una, pero no tenía Internet. ¿Qué pasaba entonces? Una directora dispuesta y preocupada por la utilización de las TIc. Estudiantes dispuestos a aprender, cuatro facilitadores tecnológicos... y la experiencia funcionó a medias. ¿Es sólo culpa de docentes que se niegan a incorporar las TIC, que no se actualizan? Es fácil culpar siempre al docente pero la cuestión es más compleja. ¿Cómo los formaron? ¿Cómo forman a los docentes actuales? ¿Qué políticas públicas acompañan esa formación? ¿Puede una escuela desarrollar todo el potencial sin conectividad? ¿Es sólo cuestión de llenar la escuela de dispositivos y ya? ¿Es sólo encontrar docentes dispuestos? (Entrevista, docente, 50 años, AMBA).

Más allá de las limitaciones de tener sólo uno o dos carritos tecnológicos para toda una escuela (y que muchas no tienen ninguno), este modelo también conlleva otras tensiones. Los docentes señalan que es necesario incrementar la conectividad en las escuelas para aprovechar el potencial de los teléfonos móviles. Dado que la mayoría de los estudiantes no dispone de datos móviles, el uso académico de las TIC se ve limitado.

\subsection{El teléfono móvil: dispositivo omnipresente y conflictivo}

El teléfono móvil es el dispositivo tecnológico más utilizado por la mayoría de jóvenes. En el aula, su uso escolar reside principalmente en buscar información sobre temáticas abordadas en clase. También es utilizado para intercambiar información o tareas en red, sea a través de páginas en plataformas de redes sociales como Facebook o grupos creados en programas de mensajería instantánea como Whatsapp. En efecto, al igual que en los foros y chats, se lee y escribe de manera colectiva, como señala una docente de Lengua y Literatura:

El celular en el aula es muy útil. Lo uso para buscar información, usar la app de diccionario, escribir textos de manera colectiva, leer cuentos, novelas, artículos, etc. Como la escuela cuenta con aula virtual, solemos acceder a ésta desde los teléfonos para descargar material o enviar mails. También hacemos un uso recreativo. Mis alumnos pueden escuchar música cuando trabajan, si eso los ayuda a concentrarse, y pueden jugar una vez que terminaron de hacer sus actividades. Creo que la lucha contra el celular en el aula es una batalla perdida y que hay que encontrar formas de integrarlo al trabajo diario. Las TIC son un gran complemento para el trabajo docente en el aula y en los momentos personales de estudio. La realidad es que los celulares tienen cada vez más aplicaciones que, bien utilizadas, pueden ser muy provechosas para organizar el tiempo, concentrarse, buscar información, desarrollar ideas creativas, etc. En mi caso, desde tutoría, tratamos también de educar en el uso provechoso de las TIC. (Entrevista, docente, 35, AMBA).

La decisión de utilizar el dispositivo suele quedar en la figura docente, quien decide en función de su trayectoria socio-tecnológica y el feedback que encuentra entre sus pares docentes, los directivos y cada grupo de estudiantes. En todo caso, implementar las TIC en el aula de manera "armoniosa" exige dedicación, empatía y paciencia por parte de la figura docente para establecer consignas, límites y 
objetivos precisos en un campo en el que ningún actor sabe bien qué es lo adecuado.

El uso de las TIC en el aula tiene otros tiempos, a veces hay que explicar la aplicación, probar. Las clases también tienen otra dinámica, que a veces no es bien vista por el directivo. Por ejemplo, yo uso mucho el celular en clase, pero en la escuela no les gusta que los alumnos usen sus celulares en el aula. (Entrevista, docente, 34 años, Río Negro).

El teléfono es un foco de distracción que los pibes tienen en el bolsillo. Es muy difícil el día a día, pero haciendo pactos previos se puede regular y ayudar a los chicos a que entiendan en qué momentos usarlo. Suele ser complicado cuando los adolescentes ven que los adultos a su alrededor pasan demasiado tiempo usando el teléfono. (Entrevista, docente, 30, AMBA).

Una docente señala que el teléfono móvil es la herramienta que utilizan todos, tanto docentes como estudiantes, y que por eso no es necesario a priori mayor equipamiento. Lo que sí es necesario -resaltaes conectividad y capacitaciones centradas en lo pedagógico, no sólo en la cuestión técnica.

Hay que asegurar conectividad y cambiar las perspectivas de las capacitaciones, no sólo focalizando en lo técnico, sino también en lo pedagógico. El teléfono móvil es la herramienta transversal a docentes y alumnos. Por eso hay que fomentar su uso pedagógico. Si bien, como toda nueva herramienta, soluciona algunos problemas, muchas veces trae otros. Habría que dinamizar las visiones de la institución escolar; si no, la tecnología al ser dinámica va a sacarle mucha distancia a la escuela, que en estas cuestiones funciona en forma lenta. Con docentes capacitados con libertad de acción en el aula, estas distancias pueden acortarse. (Entrevista, docente, 36 años, AMBA).

Permitir el uso libre o con mínimas restricciones de los celulares implica empoderar a los estudiantes. ¿Están preparados para ello directivos y docentes? Y si no lo están, quizás sea tiempo de ayudarlos a capacitarse, asesorarlos y respaldarlos en la incorporación de una mirada y un uso crítico de estas tecnologías. Quizás nadie esté preparado para esta nueva libertad, y todos necesitemos nuevas normas y estrategias para redireccionar los procesos de aprendizaje en tiempos de esta cultura digital móvil.

\subsection{Más allá del imperativo tecnológico: para qué las tic en las aulas}

Entre las prácticas que pueden desarrollarse en el aula, se encuentra la utilización de las TIC con el objeto de facilitar la transmisión de los conceptos científicos. A pesar de esto, en general las TIC sólo son aplicadas como un método auxiliar. En consecuencia, el aprendizaje sigue centrándose en la figura docente como orador predominante, lo que suele implicar bajos niveles de participación.

Un problema central se relaciona con el inmenso caudal informativo que se encuentra disponible en la Web, aunque difusamente jerarquizado. Esto confunde a una parte de los estudiantes, que encuentran dificultades para distinguir la veracidad y precisión entre datos de múltiples fuentes.

A veces damos por hecho que los estudiantes tienen ciertas habilidades y esto no siempre es así. ¿Saben discernir entre fuentes de información fiables y poco fiables? ¿Saben usar herramientas informáticas? A veces no saben usar el programa Word ni el PowerPoint ni mandar un mail. (Entrevista, docente, 51 años, Jujuy).

Docentes y estudiantes suelen experimentar las consecuencias de la distracción en la red: la gran cantidad de contenidos, herramientas, servicios y estímulos dificultan el avance en la dinámica escolar.

La escuela frena al docente innovador en forma y contenido, porque hay un "imaginario" de cuanta más cantidad de contenido, mejor. Hay formatos estandarizados para las planificaciones; no es bien visto y cuesta salir de ese esquema. No sólo es una cuestión docente, de formación e infraestructura, si no que entra la escuela que de alguna forma es conservadora. (Entrevista, docente, 37 años, AMBA). 
Los docentes ven como una imposición el uso de las tic. Falta capacitación y práctica para darles seguridad en el uso de estas tecnologías frente al curso. En cambio, los adolescentes son muy receptivos. Esperan ansiosos la llegada de las tecnologías al aula, con las que suelen realizar un uso fluido e intuitivo. (Entrevista, directivo, 58 años, Catamarca).

Más allá de este imperativo tecnológico, ni directivos, ni docentes, ni estudiantes vislumbran de qué modos incorporar las TIC a las dinámicas áulicas para potenciar las clases. La mayoría coincide en la falta de capacitación y espacios de reflexión sobre estas problemáticas, así como en los problemas de logística vinculados a la escasez de wifi y de equipos tecnológicos que sirvan para proyectar material audiovisual y trabajar en red de manera eficiente.

Como docente de secundaria, debo decir que es muy difícil trabajar con incorporación de las TIC, cuando hay escuelas que no poseen computadoras, ni chicos con computadoras en sus casas. Cuando a pesar de utilizar los celulares, los alumnos no poseen datos (y a pesar de prestar datos, no alcanza para todos) y la escuela no tiene Internet, o no lo presta, o colapsa con las conexiones en el aula... con capacitaciones de solamente 4 o 5 encuentros virtuales para el uso de las TIC. (Entrevista, docente, 41 años, AMBA).

No obstante, cuando se les interroga sobre qué tipo de capacitación creen que sería útil dar, la mayoría no aporta ideas más allá de los recursos nombrados y de la posibilidad de trabajar en red y de manera colaborativa a través de páginas denominadas wikis. El problema de la capacitación es la falta de tiempo y remuneración acorde.

Mis colegas trabajan todo el día y no pueden capacitarse. Podría haber una capacitación en la escuela como las jornadas, para poder trabajar en serio. Podrían poner más puntaje a los cursos de las TIC, para incentivar a los docentes... podrían empezar a ver cómo se trabaja en los profesorados. ¿Hay una materia dedicada a las TIC y su aplicación didáctica? No. (Entrevista, directivo, 55 años, AMBA).

Además, las virtudes del uso de las TIC representan a la vez riesgos. La posibilidad de potenciar el trabajo dentro y fuera del aula tiene, como desventaja, que el estudiantado utilice estas tecnologías para fines recreativos, difíciles de regular a nivel contenidos y tiempo de uso.

\section{Discusión y conclusiones}

Entre las distintas investigaciones que han evaluado el impacto del PCl durante los últimos años, se coincide con Welschinger (2016) en que el entusiasmo estudiantil inicial ante la llegada de las netbooks contrasta con la preocupación de docentes y directivos por la búsqueda de límites que parecerían ser "desbordados" por las nuevas tecnologías. Sin embargo, esta tensión no se circunscribe a este fenómeno singular, sino que atraviesa la relación entre tecnologías y educación formal.

En cuanto a las brechas digitales, se concuerda con Cotik y Monteverde (2016) en que existen marcadas diferencias en calidad educativa entre escuelas rurales y urbanas. A su vez, quienes concurren a las urbanas suelen tener mejores equipos de computación. En este sentido, advierten que la entrega de netbooks en escuelas rurales sí fue de mucha utilidad para la mayoría de estudiantes.

En definitiva, las netbooks generaron expectativas, motivación y una ampliación de la alfabetización sociotecnológica en sectores populares. Sin embargo, estas expectativas devinieron en cierta medida en frustración, ante la escasa inversión en capacitación docente, la poca responsabilidad estudiantil para cuidar sus aparatos y la baja predisposición de directivos para respaldar su uso de manera sistemática. Lo observado en el trabajo de campo coincide con lo relevado por otras investigaciones (Almirón, 2015).

Tanto el modelo de la sala de informática como las netbooks y el "carrito tecnológico" comparten la escasa relación que suele existir entre lo aprendido en este espacio y en el resto de las materias. Uno de los errores comunes de numerosos análisis es centrar la responsabilidad en el rol docente. También son 
centrales las políticas públicas, los directivos, la conectividad, el equipamiento, el trabajo interdisciplinar, los facilitadores tecnológicos, el acompañamiento de los padres y las capacitaciones docentes remuneradas.

El desafío de incluir las TIC en las aulas incluye a los estudiantes, quienes deben pasar de la fascinación constante en el uso de redes sociales, mensajería instantánea, streaming y videojuegos, a un uso académico de selección y apropiación del conocimiento disponible a través de las diversas herramientas que permiten gestionarlo, procesarlo y transformarlo. Esto implica, básicamente, poder concentrarse en las tareas escolares y aprender a buscar y discernir de modo eficiente fuentes informativas de calidad, siempre con el apoyo docente.

La mayoría de docentes sugiere que la formación en TIC es principalmente técnica, pero se "estudia" poco cómo usarla didácticamente. Esto sin duda promueve una formación "tradicional", en lugar de una formación "innovadora". De la Iglesia (2019), por ejemplo, sostiene que los docentes deben no sólo ser especialistas en su materia, sino también convertirse en generadores de contenidos multimedia. Esta mayor exigencia sobre el rol docente en numerosos casos no es acompañada por recursos institucionales. Esta cuestión se vio profundizada por la pandemia del CovID-19: más demanda hacia los docentes junto con una profundización de la brecha entre las escuelas privadas, con mayor cantidad de clases por videollamada, menores problemas socioeconómicos y de accesibilidad, y las escuelas secundarias públicas no universitarias, que resisten con esfuerzo docente e institucional ante la falta de presupuesto y tratan de subsanar y contemplar los problemas de conectividad de una parte del estudiantado en pos de mantener la continuidad pedagógica. Para esto, muchos docentes optan por organizar menos clases por videollamada y dar más tareas por grupos de Whatsapp mediante el envío de documentos en PDF, Word e imágenes con ejercicios.

En este sentido, los docentes, tanto antes como durante la pandemia, coinciden en los principales inconvenientes para incluir las tecnologías en las cursadas: infraestructura y equipamiento tecnológico, capacitación docente y responsabilidad estudiantil frente al desafío de mayor autonomía. Dentro de la capacitación, se vuelve necesario "desaprender" o modificar algunas prácticas tradicionales y aprender otras nuevas, modificando ciertos aspectos del enfoque pedagógico y la posición docente en pos de una mayor adaptabilidad y flexibilidad frente a la cultura juvenil, digital y móvil. Cómo formar estudiantes eficaces en su apropiación de las TIC aún no resulta claro, pero la ubicuidad y el uso intensivo de estas tecnologías en la cotidianidad de la mayoría se tornan decisivos para el aprendizaje.

La brecha generacional encarnada en directivos y docentes, por un lado, y estudiantes, por otro, se expresa en distintas "experiencias", miradas, tensiones, estrategias pedagógicas, dispositivos opacos para unos y obsoletos para otros. Dentro del plantel docente se vislumbra otra brecha generacional: a mayor edad, más apego al paradigma tradicional. No obstante, todas las generaciones docentes expresan cierto malestar ante la inclusión de las TIC: a docentes de mayor edad les producen inseguridades ontológicas, logísticas, pedagógicas y técnicas, así como desconfianza respecto a la utilidad en el proceso de enseñanza-aprendizaje. Quienes son más jóvenes, y suelen estar a favor de incluirlas, encuentran problemas de infraestructura y diversas tensiones con directivos, facilitadores técnicos, estudiantado y resto del plantel docente.

Esta tendencia generacional tiene sus paradojas: docentes mayores se inclinan a incluir las TIC, mientras que muchos docentes jóvenes expresan posiciones ambivalentes. Como se escucha a diario, la amplia mayoría estudiantil adhiere a incluirlas en el proceso educativo. Esta "nebulosa" de la comunidad educativa frente a la inclusión de las TIC representa un estado de situación y señala la necesidad de articular espacios de reflexión y debate con los distintos actores: funcionarios, directivos, docentes, técnicos, facilitadores tecnológicos, padres y estudiantes.

En cuanto a la búsqueda, filtrado y evaluación de contenido, se coincide con Morduchowicz (2018) y López et al. (2019) en que las generaciones jóvenes poseen dificultades para seleccionar y evaluar el inmenso caudal informativo disponible en la web. La mayoría se contenta con copiar la información encontrada en los primeros resultados. A su vez, consultan videos, diapositivas, imágenes y podcasts 
relacionados con el tema de estudio, pero poseen dificultades para extraer información y relacionar otros formatos con el texto escrito. La acumulación de evidencia empírica señala la necesidad de proveer estrategias de búsqueda que impliquen reflexión sobre las diversas fuentes y géneros comunicativos, para complementar de manera crítica y creativa la cultura letrada con la audiovisual.

Ante tanta diversidad de fuentes y proliferación de estímulos, se torna necesario que el estudiantado sea orientado para desarrollar habilidades en torno al aprendizaje independiente, la lecto-escritura a partir de distintas fuentes digitales y la organización del trabajo mediada por entornos virtuales. Sin desdeñar la cultura letrada, aprovechar el potencial de las TIc les permitirá mejorar la capacidad para resolver problemas, elevar su interés y desarrollar mayor autonomía en el aprendizaje.

El avance de las tecnologías en el mundo y en la vida cotidiana de las generaciones jóvenes resulta un hecho irrefutable. Tanto como que no es suficiente con facilitar el acceso y proveer equipamiento. Hace falta inversión estatal e institucional que se traduzca en conectividad, espacios de reflexión y capacitaciones remuneradas para docentes, así como proyectos interdisciplinarios que permitan potenciar el uso de estas herramientas. Es probable que recién frente a este conjunto de recursos podamos aprender a integrarlas en el aula de modos productivos.

La incorporación de las TIC en las currículas educativas implica un proceso complejo, dado que la problemática no es sólo tecnológica, sino que involucra las áreas de preparación docente, estrategia pedagógica y dinámica áulica. Queda para futuras investigaciones indagar la emergente propuesta de gamificación en las aulas. Se promueve que futuras políticas públicas aspiren a una inclusión digital desde una perspectiva integradora, no sólo considerando la cuestión del acceso, sino también permitiendo a los sujetos con menos capitales desarrollar destrezas digitales valoradas socialmente.

\section{Agradecimiento}

A estudiantes-docentes de la Licenciatura en Tecnologías Digitales para la Educación, de la Universidad Nacional de Lanús, por los aportes realizados.

\section{Referencias}

Almirón, M. (2015). La situación de las tIC en la educación argentina: un estudio de casos en dos escuelas bonaerenses (Tesis doctoral). Universidad Nacional de Quilmes. https://ridaa.unq.edu.ar/handle/20.500.11807/101

Arancibia, B. y Bustamante, M. (2019). Aprendizaje lector con apoyo de la pizarra digital interactiva: estudio empírico. Magis, Revista Internacional de Investigación en Educación, 12(24), 25-40.

https://doi.org/10.11144/Javeriana.m12-24.alpd

Armella, J. (2016). Hacer docencia en tiempos digitales. Un estudio socio-pedagógico en escuelas secundarias públicas emplazadas en contextos de pobreza urbana. Estudios Pedagógicos, 42(3), 49-67. http://dx.doi.org/10.4067/S0718-07052016000400003

Beltrán-Sánchez, J. A., García, R. I., Ramírez-Montoya, M. S. y Tánori, J. (2019). Factores que influyen en la integración del Programa de Inclusión y Alfabetización Digital en la docencia en escuelas primarias. Revista Electrónica de Investigación Educativa, 21(e31), 1-11.

https://doi.org/10.24320/redie.2019.21.e31.2088

Benítez, S. (2018). La experiencia juvenil del tiempo y el espacio a partir de la apropiación de las tecnologías de información y comunicación en La Plata (Argentina). Andamios, 15(43), 343-368.

https://dx.doi.org/10.29092/uacm.v15i36.613 
Blanco, M., Ramos, F. y Sánchez, P. (2018). Situación de la integración de las Tic en los centros educativos. Un estudio de casos. Digital Education Review, 34, 27-43.

http://revistes.ub.edu/index.php/der/article/view/20165

Cabello, R. (2017). La vida en los bordes. Reflexiones sobre el acceso a las tecnologías y la inclusión digital. Psicología, Conocimiento y Sociedad, 7(2), 252-278. https://doi.org/10.26864/PCS.v7.n2.11

Cotik, V. y Monteverde, H. (2016). Evolución de la enseñanza de la informática y las TIC en la escuela media en Argentina en los últimos 30 años. Virtualidad, Educación y Ciencia, 7(12), 11-33.

https://revistas.unc.edu.ar/index.php/vesc/article/view/14793

de la Iglesia, M.C. (2019). Caja de herramientas 4.0 para el docente en la era de la evaluación por competencias. Innovación Educativa, 19(80), 93-112. https://www.ipn.mx/innovacion/abstracts/ie-80/cajade-herramientas-4-0-para-el-docente.html

de Lima, M. y Moreira, I. (2019). Significado que los docentes le dan a la integración de tecnologías digitales en sus prácticas pedagógicas. ALTERIDAD. Revista de Educación, 14(1), 12-25.

https://doi.org/10.17163/alt.v14n1.2019.01

Díaz-Vicario, A., Mercader, C. y Gairín, J. (2019). Uso problemático de las TIC en adolescentes. Revista Electrónica de Investigación Educativa, 21, 1-11. https://doi.org/10.24320/redie.2019.21.e07.1882

García-Martín, S. y Cantón-Mayo, I. (2019). Uso de tecnologías y rendimiento académico en estudiantes adolescentes. Comunicar, 59(27), 73-81. https://doi.org/10.3916/C59-2019-07

Gruschetsky, M. y Serra, J. (2001). Las tecnologías de la información y la comunicación. El equipamiento informático en las escuelas de EGB: disponibilidad y uso. Ministerio de Educación, Ciencia y Tecnología.

Huertas, A. y Pantoja, A. (2016). Efectos de un programa educativo basado en el uso de las Tic sobre el rendimiento académico y la motivación del alumnado en la asignatura de tecnología de educación secundaria. Educación XXI, 19(2), 229-250. https://doi.org/10.5944/educxx1.16464

Kozak, D. (2016). Caso: aulas en red. En A. Artopoulos y C. Lion (Eds.), La escuela de las pantallas. Referentes y casos para la transición (pp. 13-40). Fundación Telefónica/Ariel.

Lemus, M. (2017). De accesos e igualaciones. Apropiaciones de tıc por jóvenes en el marco del Programa Conectar Igualdad. Ciencia, docencia y tecnología, 28(54), 150-187.

http://pcient.uner.edu.ar/index.php/cdyt/article/view/259/0

Linne, J. (2018). En torno a la integración tecnológica en espacios educativos. ¿Nuevos problemas y nuevas soluciones? Propuesta Educativa, 49(1), 73-83. http://propuestaeducativa.flacso.org.ar/wpcontent/uploads/2019/11/Propuesta-Educativa-49-articulos-Linne.pdf

López, C. (2016). El videojuego como herramienta educativa. Posibilidades y problemáticas acerca de los serious games. Apertura. Revista de Innovación Educativa, 8(1), 1-15.

http://www.udgvirtual.udg.mx/apertura/index.php/apertura/article/view/825/539

López, M., Garro, E. y Egaña, T. (2019). La lectura digital en un aula de secundaria: prácticas reales y dificultades del alumnado. Píxel-Bit. Revista de Medios y Educación, 55, 99-116.

https://doi.org/10.12795/pixelbit.2019.i55.06

Martín, M. (2018). Innovación pedagógica de las TIC y la gamificación en los estilos de aprendizaje. Educación y Futuro Digital, 16, 133-149. 
Matamala, C. (2018). Desarrollo de alfabetización digital ¿Cuáles son las estrategias de los profesores para enseñar habilidades de información? Perfiles Educativos, 40(162), 68-85.

https://doi.org/10.22201/iisue.24486167e.2018.162.58846

Morduchowicz, R. (2018). Ruidos en la Web. Cómo se informan los adolescentes en la era digital. Mondadori.

Noshahr, R., Talebi, B. y Mojallal, M. (2014). The relationship between use of cell-phone with academic achievement in female students. Applied Mathematics in Engineering, Management and Technology, 2(2), 424-428.

Ortiz-Colón, A., Jordán, J. y Agredal, M. (2018). Gamificación en educación: una panorámica sobre el estado de la cuestión. Educação e Pesquisa, 44, e173773.

http://dx.doi.org/10.1590/s1678-4634201844173773

Park, S. (2017). Digital capital. Palgrave Macmillan.

Qian, M. y Clark, K. (2016). Game-based Learning and 21st century skills: a review of recent research. Computers in Human Behavior, 63, 50-58. https://doi.org/10.1016/j.chb.2016.05.023

Sola, J., García, M. y Ortega, M. (2019). Las implicaciones del uso de dispositivos móviles en el proceso de enseñanza-aprendizaje en alumnos de $5^{\circ}$ y $6^{\circ}$ de primaria. Píxel-Bit. Revista de Medios y Educación, 55, 117131. https://doi.org/10.12795/pixelbit.2019.i55.07

Urresti, M. (2015). Nómades, convergentes, protésicos y obnubilados. Los jóvenes ante la emergencia del campo tecnológico digital. En L. Quevedo (Comp.), La cultura Argentina hoy. Tendencias (pp. 287-318). Siglo XXI.

Welschinger, N. (2016). «Nativos digitales» lejos de la naturalización. Procesos de socialización de beneficiarios de políticas de inclusión digital. Revista Argentina de Estudios de Juventud, (10), e015.

https://doi.org/10.24215/18524907e015

Zukerfeld, M. (2018). Inclusión, escuela y conocimientos: Elementos para un análisis materialista del programa Conectar Igualdad en las escuelas argentinas. Psicología, Conocimiento y Sociedad, 7(2), 134-161. https://doi.org/10.26864/PCS.v7.n2.7 